\section{Eruptive keloids after chickenpox}

\section{Nicolas Kluger, ${ }^{1,2}$ Antoine Mahé, ${ }^{3}$ \\ Bernard Guillot ${ }^{1}$}

Université de Montpellier I, Service de

Dermatologie, Hôpital Saint-Eloi,

Montpellier, France;

2Departments of Dermatology,

Allergology and Venereology, Institute of Clinical Medicine, University of Helsinki,

Skin and Allergies Hospital, Helsinki

University Central Hospital, Helsinki,

Finland; 3Service de dermatologie, Hôpital Pasteur (HCC) Colmar Cedex, France

\begin{abstract}
Hypertrophic scars and keloids result from abnormal wound healing in predisposed individuals. They occur within months of cutaneous trauma (surgical wounds, piercing, lacerations) or inflammation (acne, folliculitis, vaccination site). They have rarely been reported after chickenpox. Herein we report a dramatic case in a 4-year-old black girl and discuss the issues related to the management of hypertrophic scars and keloids in this peculiar situation.
\end{abstract}

\section{Introduction}

Hypertrophic scars and keloids result from an abnormal wound healing process in predisposed individuals. They occur within months of a cutaneous trauma or inflammation. We report a dramatic case in a young black girl after chickenpox.

\section{Case report}

A 4-year-old Congolese girl was referred for numerous raised skin lesions on chickenpox scars. Chickenpox occurred 4 months earlier, without complications and 3 weeks prior to consultation, new cutaneous lesions abruptly appeared. The patient had numerous (over 30) scattered, small, firm, pruritic, darkskinned coloured nodules on the chest, shoulders, flanks and upper arms (Figures 1 and 2). Lesions were restricted to the chickenpox scars but infiltrated into surrounding normal tissue, favouring keloids rather than hyper- trophic scars. Examination was otherwise unremarkable. There was no similar familial history. The localisation, the number of lesions and her age, prompted to initiate pressure therapy with a custom-made compressive garment that had to be worn 23 hours a day for at least 6 months.

\section{Discussion}

Hypertrophic scars and keloids, which result from abnormal wound healing in predisposed individuals, ${ }^{1}$ occur within months of cutaneous trauma (surgical wounds, piercing, lacerations) or inflammation (acne, folliculitis, vaccination site). They are located mainly on the upper part of the body (earlobes, neck, shoulders, back), may be pruritic or painful, and do not regress spontaneously. ${ }^{1}$ Chickenpox is a rare cause of keloids described since the 1960s: the lesions occur as either small eruptive keloids or gigantic and monstrous ones on the chickenpox scars. ${ }^{2-4}$ Numerous treatments have been proposed with varying degrees of efficacy: surgical excision, intralesional corticosteroid injections, cryotherapy, topical silicone gel, laser therapy, and 5-fluorouracil and bleomycin injections, ${ }^{1}$ among others. Our case illustrates the issues related to the management of a young dark-skinned pre-pubertal girl. The high number of lesions, the young age, and the skin phototype were contraindications for a wide range of treatments, including highly potent local corticosteroid ointments, intralesional corticosteroid injections and cryotherapy. All are efficient but painful and expose to transitory hypopigmentation. Repeated steroid injections can lead to adverse systemic effects. Laser must be used with caution in dark-skinned patients. Therefore, we proposed pressure therapy as it is widely used for burn scar patients. ${ }^{5}$ Its precise mechanism of action is not understood but pressure appears clinically to enhance the scar maturation process. ${ }^{1}$ However, the efficacy has never been proven in scientific or clinical trial and the optimum pressure for treatment is not known. ${ }^{5}$ The vest must be worn by the patient almost 24 hours a day and success is related to compliance as pressure garment therapy exposes to overheating, pruritus, cutaneous rash and abnormal bone growth. ${ }^{5}$ In our case, garment can be changed every three months to follow the growth of the child. Our case is a reminder of the burden of darkskinned individuals exposed to the risk of keloids and their cosmetic consequences. It illustrates the difficulties in the management of young children when the lesions are scattered over the body.
Correspondence: Nicolas Kluger, Departments of Dermatology, Allergology and Venereology,, Skin and Allergies Hospital, Helsinki University Central Hospital, Meilahdentie 2, P.O. Box 160, FI-00029 HUS, Finland.

E-mail: nicolaskluger@yahoo.fr

Key words: keloid, chickenpox, scar, cicatrix, child.

The mother of the patient gave consent for publication of the pictures.

Received for publication: 15 July 2011.

Accepted for publication: 20 July 2011.

This work is licensed under a Creative Commons Attribution NonCommercial 3.0 License (CC BYNC 3.0).

(C) Copyright N. Kluger et al., 2011

Licensee PAGEPress, Italy

Dermatology Reports 2011; 3:e15

doi:10.4081/dr.2011.e15

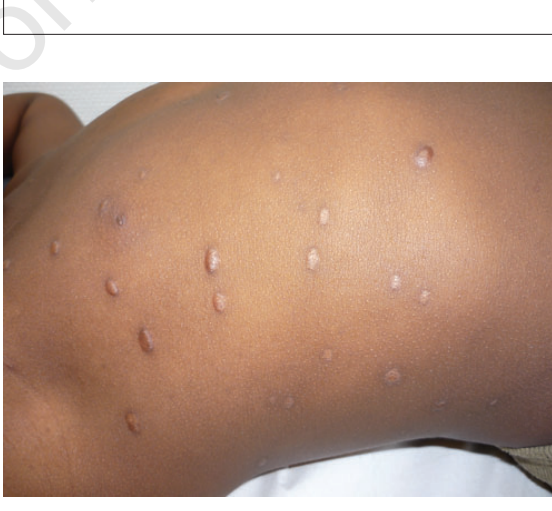

Figure 1. Eruptive keloids of the trunk on chickenpox scars.

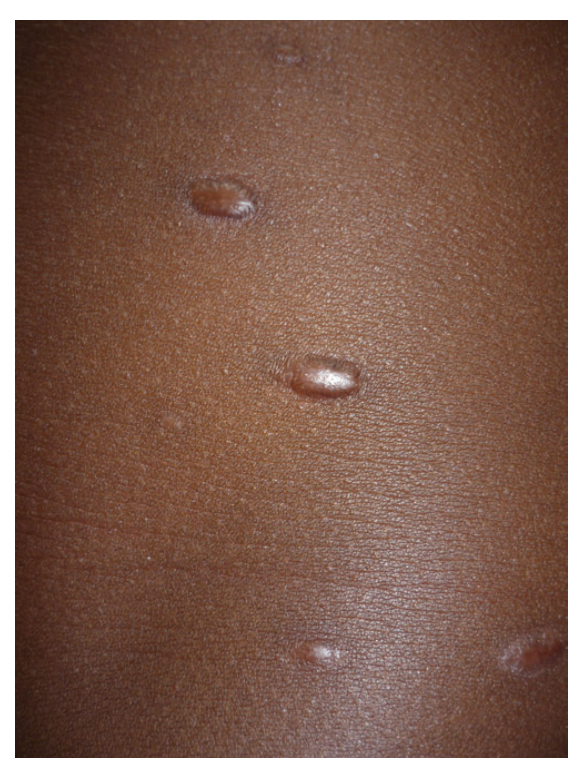

Figure 2. Close up view of the lesions. 


\section{References}

1. Wolfram D, Tzankov A, Pülzl P, et al. Hypertrophic scars and keloids--a review of their pathophysiology, risk factors, and therapeutic management. Dermatol Surg
2009;35:171-81.

2. Scheinfeld N, Cohen SR. Varicella causes skin pits and keloids--more reasons for the varicella vaccine. Pediatrics 2000;106:160.

3. Duperrat B, Puissant A, Goetschel GE, et al. Monstrous keloid. Bull Soc Fr Dermatol Syphiligr 1972;79:210-11.
4. Matheis H. Keloid eruption following chickenpox. Dermatologica 1971;143:31927.

5. Macintyre L, Baird M. Pressure garments for use in the treatment of hypertrophic scars - a review of the problems associated with their use. Burns 2006;32:10-15. 